\title{
DÜBLIN
}

Technological University Dublin

ARROW@TU Dublin

2016-11-14

\section{A Dual Band 450LTE/GSM900 PIFA for Portable Devices}

\author{
Abraham Loutridis \\ Technological University Dublin \\ Kansheng Yang \\ Technological University Dublin \\ Matthias John \\ Trinity College Dublin, matthias.john@tudublin.ie
}

See next page for additional authors

Follow this and additional works at: https://arrow.tudublin.ie/ahfrccon

Part of the Systems and Communications Commons

\section{Recommended Citation}

Loutridis, A., Yang, K., John, M., \& Ammann, M. J.(2016) A Dual Band 450LTE/GSM900 PIFA for Portable Devices, LAPC - Loughborough Antennas \& Propagation Conference, 2016

This Conference Paper is brought to you for free and open access by the Antenna \& High Frequency Research Centre at ARROW@TU Dublin. It has been accepted for inclusion in Conference Papers by an authorized administrator of ARROW@TU Dublin. For more information, please contact arrow.admin@tudublin.ie, aisling.coyne@tudublin.ie, gerard.connolly@tudublin.ie. Funder: SFI 
Authors

Abraham Loutridis, Kansheng Yang, Matthias John, and Max Ammann

This conference paper is available at ARROW@TU Dublin: https://arrow.tudublin.ie/ahfrccon/44 


\section{A Dual Band 450LTE/GSM900 PIFA for Portable Devices}

\author{
Abraham Loutridis \\ Research Centre for \\ Future Networks and \\ Communications \\ (CONNECT) \\ Trinity College Dublin \\ Dublin, Ireland \\ loutrida@tcd.ie
}

\author{
Kansheng Yang \\ Research Centre for \\ Future Networks and \\ Communications \\ (CONNECT) \\ Dublin Institute of Technology \\ Dublin, Ireland \\ kansheng.yang@mydit.ie
}

\author{
Matthias John \\ Research Centre for \\ Future Networks and \\ Communications \\ (CONNECT) \\ Trinity College Dublin \\ Dublin, Ireland \\ johnm@tcd.ie
}

\author{
Max J. Ammann \\ Antenna \&High \\ Frequency \\ Research Centre \\ Dublin Institute of \\ Technology \\ Dublin, Ireland \\ max.ammann@dit.ie
}

\begin{abstract}
A dual band PIFA antenna for portable devices is presented. It operates in the 450 LTE (449 - $461 \mathrm{MHz})$ and GSM $900(876-922 \mathrm{MHz})$ frequency bands. The proposed antenna which has a very compact size of $7\left(0.01 \lambda_{0}\right) \times 7 \times 70\left(0.1 \lambda_{0}\right) \mathrm{mm}^{3}$ and is suitable to integrate in small envelopes, consists of two branches and a metallic patch. The low cost and easily fabricated antenna offers high total efficiency and gain in both bands. Measured and simulated results are provided.
\end{abstract}

Keywords- Planar Inverted-F-Antenna, Compact Antenna, Portable Device, 450 LTE, GSM 900

\section{INTRODUCTION}

The ongoing trend to lower frequencies offers promising opportunities for terrestrial mobile and Machine-to-Machine applications (M2M). The 450 LTE band for mobile and fixed communication has become more attractive compared with higher bands [1], it requires a smaller number of base stations to give a broad service, covering large areas with a distributed population. The corresponding specifications of this new band, defined as Band 31 is available as part of LTE Release 12 specifications maintaining backward compatibility with all previous LTE Releases [2].

The new band is allocated in two sub-bands of $7 \mathrm{MHz}$ each in the frequency ranges $451-458 \mathrm{MHz}$ and $461-468 \mathrm{MHz}$ to fixed and mobile radio services operating in frequency division duplex mode. In Band 31, instead of narrower 1.4 or $3 \mathrm{MHz}$ channels, the optimal channelization scheme that maximizes cell throughput is achieved with $5 \mathrm{MHz}$ channels. The deployment in the sub-bands allocated by Anatel [3] to a frequency spacing between uplink $(452-457 \mathrm{MHz})$ and downlink (462 - 467 MHz) of only $5 \mathrm{MHz}$ [4-6].

As antenna sizes for mobile devices decrease due to the limited available space, the performance becomes more challenging at the lower UHF frequencies in a dimensional trade-off. In the literature there are few reported works on embedded antennas in the 450 LTE band. However, there are a variety of techniques used to reduce monopole size, including folding [7] and normal mode helical techniques [8], but these are not appropriate for integration in packaging. In $[7,8]$ the antenna efficiency is not reported and in [8] the antenna measured peak gain is not better than $-1.5 \mathrm{dBi}$ at $450 \mathrm{MHz}$. A multiband planar antenna based on a meandered structure is described in [9] covering the full 450 LTE band. The antenna located on a large ground plane of $200 \mathrm{~mm} \times 100 \mathrm{~mm}$ with no reported efficiency and gain. Lumped elements and diode varactors are also used to improve matching, bandwidth and control the resonant frequency but can increase cost and decrease antenna gain to less than $-8 \mathrm{dBi}[10,11]$. In [12-13], high permittivity magneto-dielectric ceramic materials are used to reduce the antenna size. Both antennas are located on a large ground plane size $(230 \mathrm{~mm} \times 130 \mathrm{~mm})$ with reported realized gain of $-5 \mathrm{dBi}$ (measured) [12] and $-7.5 \mathrm{dBi}$ (simulated) [13] at $450 \mathrm{MHz}$. In [14] the $117 \times 60 \times 5 \mathrm{~mm}^{3}$ MIMO antenna is described providing a $-9 \mathrm{dBi}$ maximum simulated realized gain at $450 \mathrm{MHz}$. The efficiency is not reported.

In this paper a dual band planar inverted-F-antenna for portable devices is presented. The low-cost, easy to manufacture compact antenna is low-profile, easy to package and provides omnidirectional radiation characteristics with excellent total efficiency, given its size.

\section{ANTENNA CONFIGURATION}

Fig. 1 shows the geometry of the proposed antenna, which is located on a ground plane of a single sided FR-4 substrate $(\varepsilon r=4.1, \tan \delta=0.025)$ of dimension $130 \mathrm{~mm} \times 70 \mathrm{~mm}$ (Fig. 2) with metallization thickness of $0.035 \mathrm{~mm}$. The ground plane represents a typical portable device PCB. The antenna consists of three printed FR-4 layers (front, back and top) forming a hollow block with dimensions $7 \times 70 \times 1.5 \mathrm{~mm}^{3}$. At the front layer a feeding strip of $2.94 \mathrm{~mm}$ width is located $10 \mathrm{~mm}$ from the left edge of the antenna. The shorting strip is shorted to the ground plane and consists of two strips (width $0.3 \mathrm{~mm}$ ) with horizontal and vertical length $5 \mathrm{~mm}$ and $1.8 \mathrm{~mm}$, respectively. The left arm goes to the left side on the top layer, extended along the left side and then connect to the lower strip $(c)$ at the back layer. The right arm heads to the right side along the edge of the top layer and is connected to the upper strip $(a)$ at the back layer. All the strips are printed horizontally to the ground

The project is funded by Science Foundation Ireland and is co-funded under the European Regional Development Fund under Grant No. 13/RC/2077. 
plane with the width of $0.2 \mathrm{~mm}$, lower (c) and upper (a) strips on the back side of the antenna are separated by distance $(b)$.

On the top part of the antenna a long rectangular patch of $69.2 \mathrm{~mm} \times 6 \mathrm{~mm}$ is loaded in order to improve the impedance bandwidth of both resonances. As shown in Fig. 4 the loaded patch improves the $-6 \mathrm{~dB}$ impedance bandwidth from 9.5 to 11.7 $\mathrm{MHz}$ for the first resonance and from 45.5 to $50 \mathrm{MHz}$ for the second resonant frequency. The antenna is fed using a $50 \Omega$ microstrip line (width $=2.94 \mathrm{~mm}$ ) with a SMA connector below the ground plane.

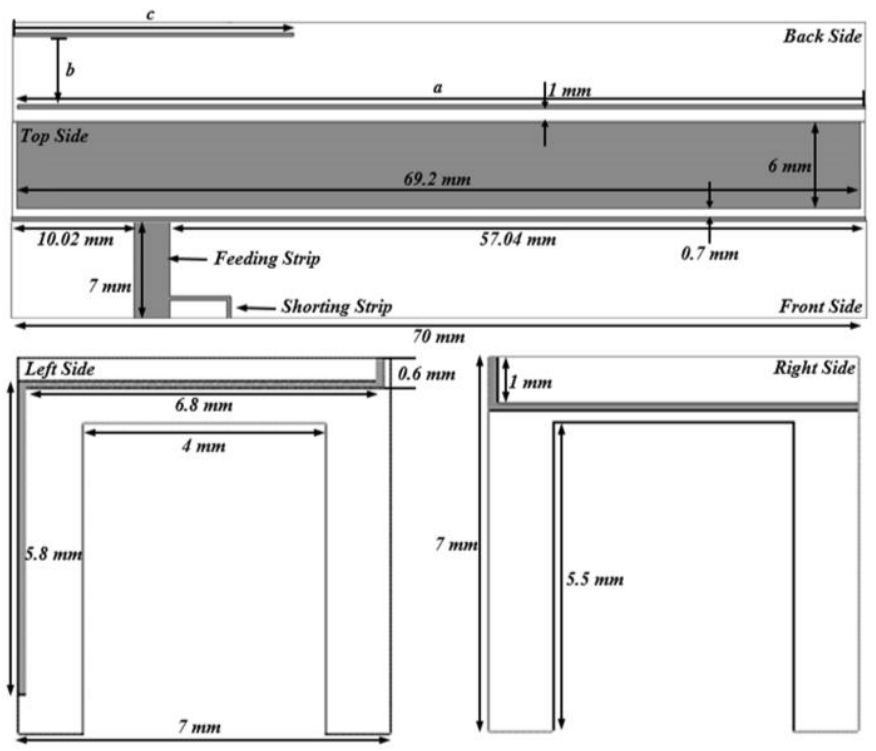

Fig. 1. Antenna geometry.

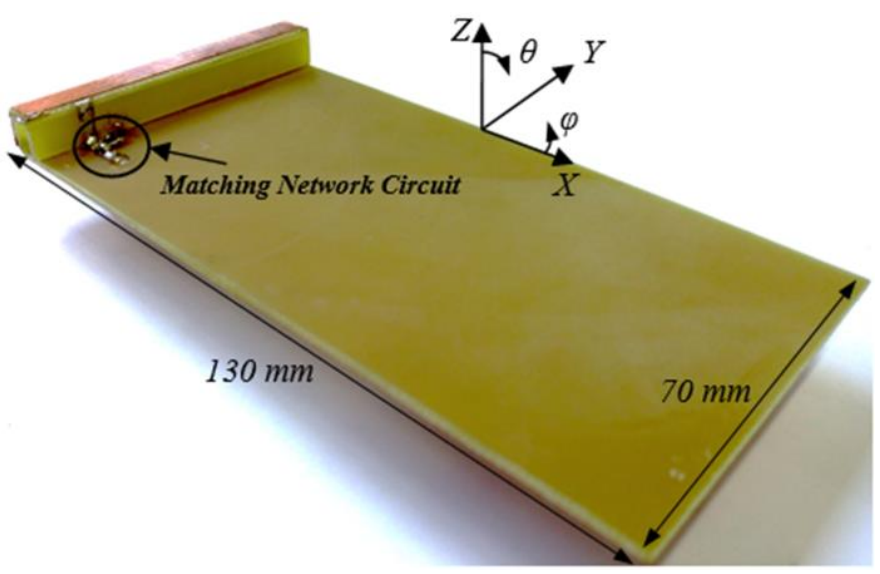

Fig. 2. Antenna prototype and coordinate system.

In order to improve the antenna bandwidth at both frequencies, a four element matching network circuit is added (Fig. 3) so that the impedance bandwidth at both frequencies is wider. The matching network consists of two parallel and one serial capacitor of $1.2 \mathrm{pF}, 1.5 \mathrm{pF}$ and $3.3 \mathrm{pF}$ respectively and one serial inductor of $12 \mathrm{nH}$. For the simulation model without the matching network the antenna for the first resonance provides a $-6 \mathrm{~dB}$ impedance bandwidth of $5.4 \mathrm{MHz}$, while for the proposed antenna the $-6 \mathrm{~dB}$ impedance bandwidth is 11.7 $\mathrm{MHz}$ (Fig. 4). For the second resonance the matching circuit improves the impedance matching from $-9.5 \mathrm{~dB}$ to $-20.5 \mathrm{~dB}$.

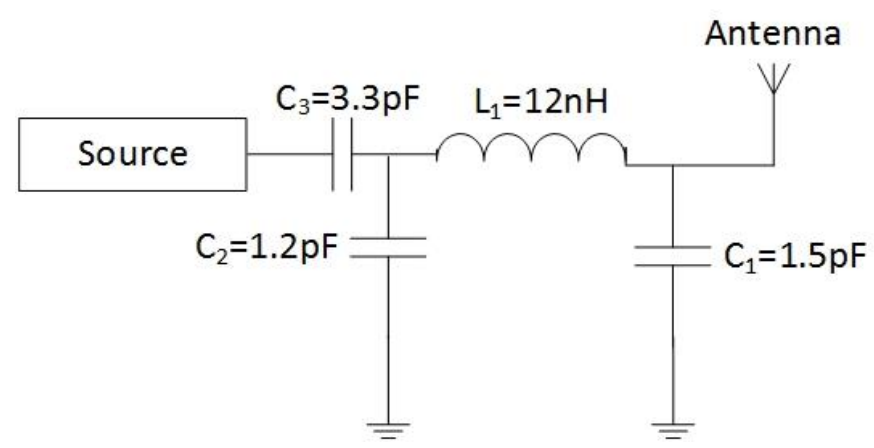

Fig. 3. Matching network circuit.

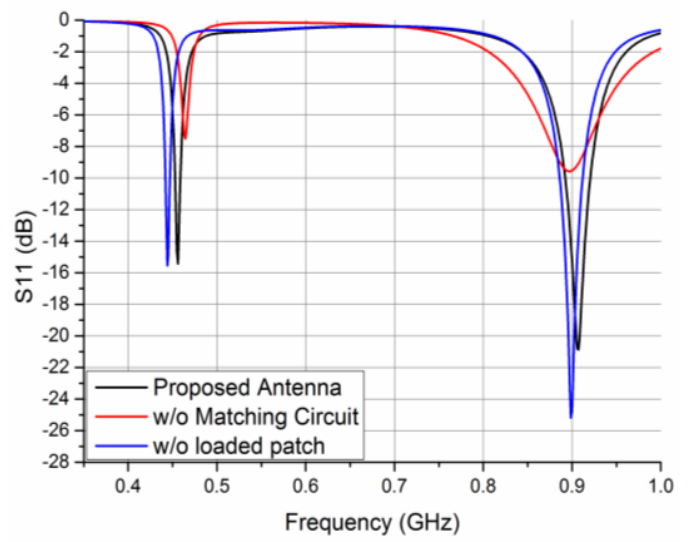

Fig. 4. Simulated $S_{11}$ results for different configurations.

\section{PARAMETRIC STUDY}

CST MWS was used to carry out a parametric study of three key geometrical parameters of the proposed PIFA antenna which are depicted on Fig. 1. The proposed values of the parameters were optimized to obtain the desired resonance bands.

Fig. 5 shows the simulated $S_{11}$ as a function of the length (a) of the upper long strip located at the rear side of the antenna. From the graph it is seen that increasing the length $(a)$ of the upper strip shifts both resonant frequencies downwards but mainly the lower frequency. By selecting the proper value of the length $a=69.6 \mathrm{~mm}$ can be tuned both resonances to the desired values.

In Fig. 6 the simulated $S_{11}$ results for the separation distance $(b)$ between the upper and the lower strips at the back side of the antenna are shown. As the separation distance $(b)$ increases the coupling effect between the two strips decreases and affects both resonances but mainly the upper one. The frequency-ratio between the upper and the lower resonant frequency $F_{r}=f_{u} / f_{l}$ continuously increases from 1.6 to 2.2 as the value of $(b)$ changes from $7.4 \mathrm{~mm}$ to $0.4 \mathrm{~mm}$. The desirable frequency-ratio for the proposed antenna is 1.98 which is achieved when $(b)$ is $5.5 \mathrm{~mm}$. 


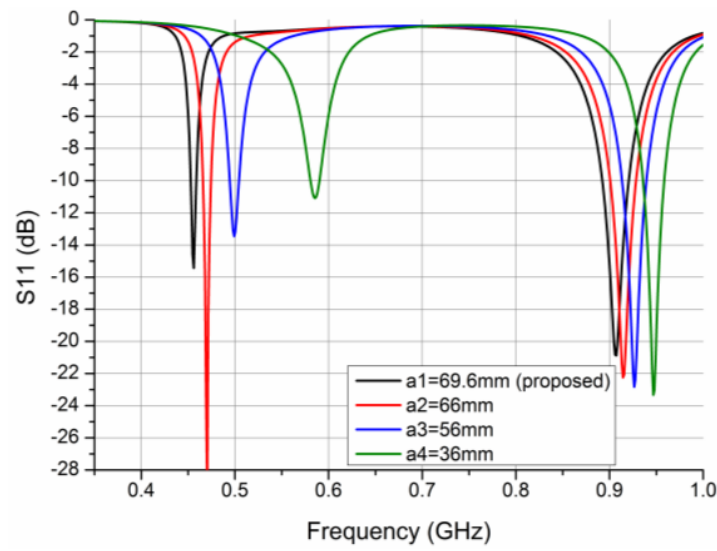

Fig. 5. The simulated $S_{11}$ dependence on the length $(a)$ of the upper back side strip of the antenna.

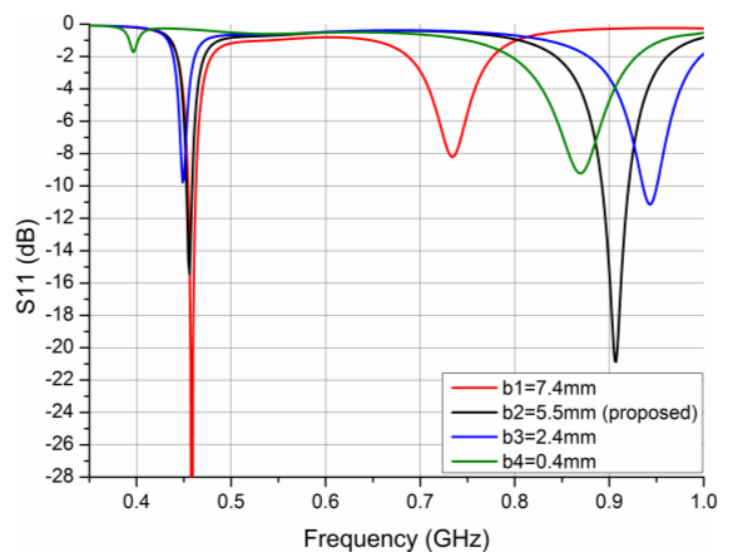

Fig. 6. The simulated $S_{11}$ dependence on the separation distance $(b)$ between the upper and the lower back side strips of the antenna.

Finally, in Fig. 7 the simulated $S_{11}$ results of the variation of the length $(c)$ of the lower rear side strip are shown. The obtained results clearly show that the second resonant frequency is heavily dependent on this parameter. As the length of the lower rear side strip increases the second resonance can be strongly controlled (frequency shifting and impedance matching) and the impedance matching of the first resonance deteriorates. The optimized value of the parameter $(c)$ for the proposed antenna is $23 \mathrm{~mm}$, providing good matching for the desirable bands.

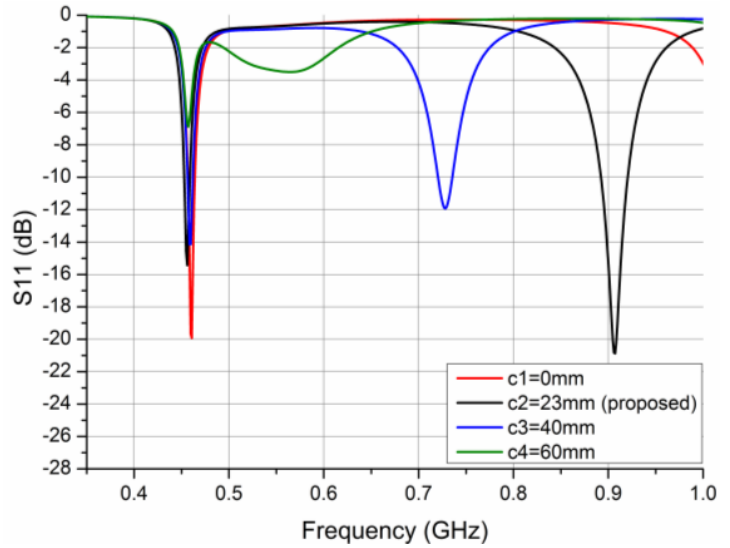

Fig. 7. The simulated $S_{11}$ dependence on the length $(c)$ of the lower backside strip of the antenna.

\section{Simulated AND MEASUREd Results}

Fig. 8 shows the measured and simulated $S_{11}$ to be in good agreement. The measured impedance bandwidth $\left(\mathrm{S}_{11} \leq-10 \mathrm{~dB}\right)$ for the first resonance is $452.5-458.6 \mathrm{MHz}$ $(\mathrm{BW}=6.1 \mathrm{MHz})$ and for $\mathrm{S}_{11} \leq-6 \mathrm{~dB}$ the antenna provides impedance bandwidth of $12 \mathrm{MHz}$, i.e. $(449-461 \mathrm{MHz})$. For the upper resonance the measured $-6 \mathrm{~dB}$ and $-10 \mathrm{~dB}$ bandwidths are $26.4 \mathrm{MHz}(886-912.4 \mathrm{MHz})$ and $46.8 \mathrm{MHz}$ $(876-922.8 \mathrm{MHz})$ respectively. The simulated results provide a $-10 \mathrm{~dB}$ and $-6 \mathrm{~dB}$ impedance bandwidth of $6 \mathrm{MHz}$ $(452.7-458.7 \mathrm{MHz})$ and $11.7 \mathrm{MHz}(450-461.7 \mathrm{MHz})$ for the first band and $\mathrm{a}-10 \mathrm{~dB}$ and $-6 \mathrm{~dB}$ impedance bandwidth of $28 \mathrm{MHz}(892-920 \mathrm{MHz})$ and $50 \mathrm{MHz}(880-931 \mathrm{MHz})$ for the second band.

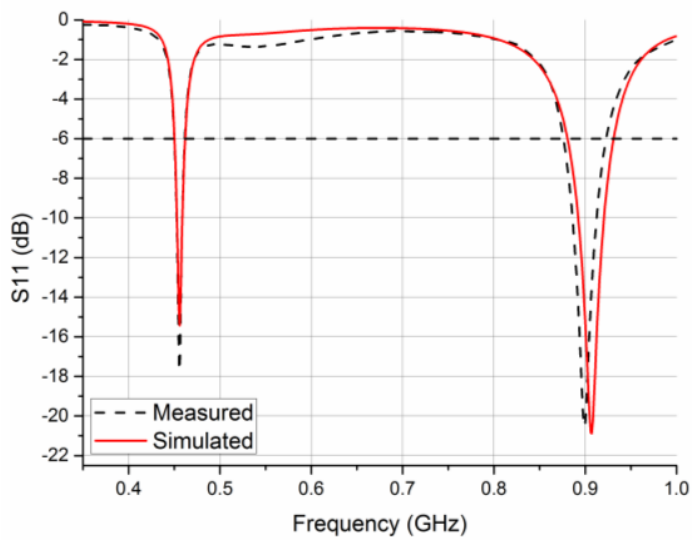

Fig. 8. Simulated and measured $\mathrm{S}_{11}$ results

For the lowest measured centre-frequency of $454 \mathrm{MHz}$ the corresponding wavelength $\lambda_{0}$ is almost $660 \mathrm{~mm}$. The embedded electrical length of the proposed PIFA antenna is $197.6 \mathrm{~mm}$ which is slightly over the $\lambda_{0} / 4$.

Simulations of the radiation and total efficiency were made for $454 \mathrm{MHz}$ and $900 \mathrm{MHz}$ using CST Microwave Studio. The measurements were performed using the Wheeler cap method [15] using a metallic box of $610 \times 610 \times 360 \mathrm{~mm}^{3}$. The measured and simulated results are in a good agreement and are listed in Table I.

TABLE I MEASURED AND SimULATED RADIATION TOTAL EFFICIENCY

\begin{tabular}{|c|c|c|c|c|}
\hline \multirow{2}{*}{$\begin{array}{c}\text { Freq. } \\
\text { (MHz) }\end{array}$} & \multicolumn{2}{|c|}{ Radiation Eff. (\%) } & \multicolumn{2}{c|}{ Total Eff. (\%) } \\
\cline { 2 - 5 } & Simulated & Measured & Simulated & Measured \\
\hline 454 & 16.5 & 17.3 & 16 & 17 \\
\hline 900 & 57.4 & 50.5 & 56 & 50 \\
\hline
\end{tabular}

In Figs. 9 and 10 the measured and simulated azimuth $(\mathrm{x}-\mathrm{z})$ and elevation $(\mathrm{x}-\mathrm{y})$ and $(\mathrm{y}-\mathrm{z})$ plane radiation patterns at $454 \mathrm{MHz}$ and $900 \mathrm{MHz}$ respectively are illustrated. The maximum measured realized gain at $454 \mathrm{MHz}$ and $900 \mathrm{MHz}$ is $-5 \mathrm{dBi}$ and $0 \mathrm{dBi}$ respectively. There is good agreement between the measured and the simulated results.

It is observed that the Phi $(\varphi)$ component provides good omnidirectional characteristics in the $\mathrm{y}-\mathrm{z}$ plane for both frequencies, as well as good polarization discrimination is also achieved. 


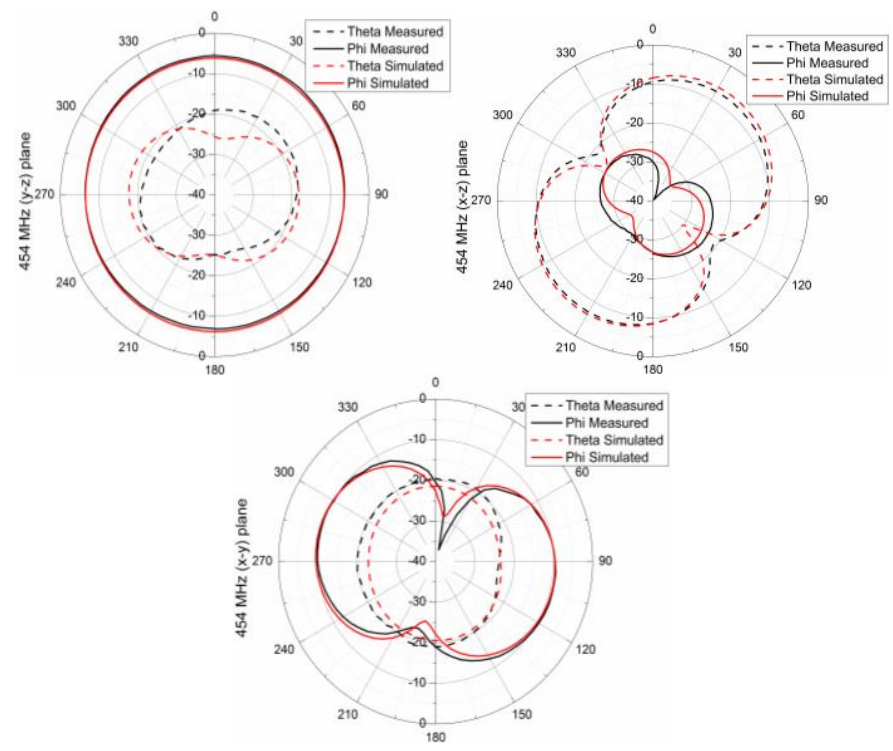

Fig. 9. Measured and simulated radiation patterns at $454 \mathrm{MHz}$.

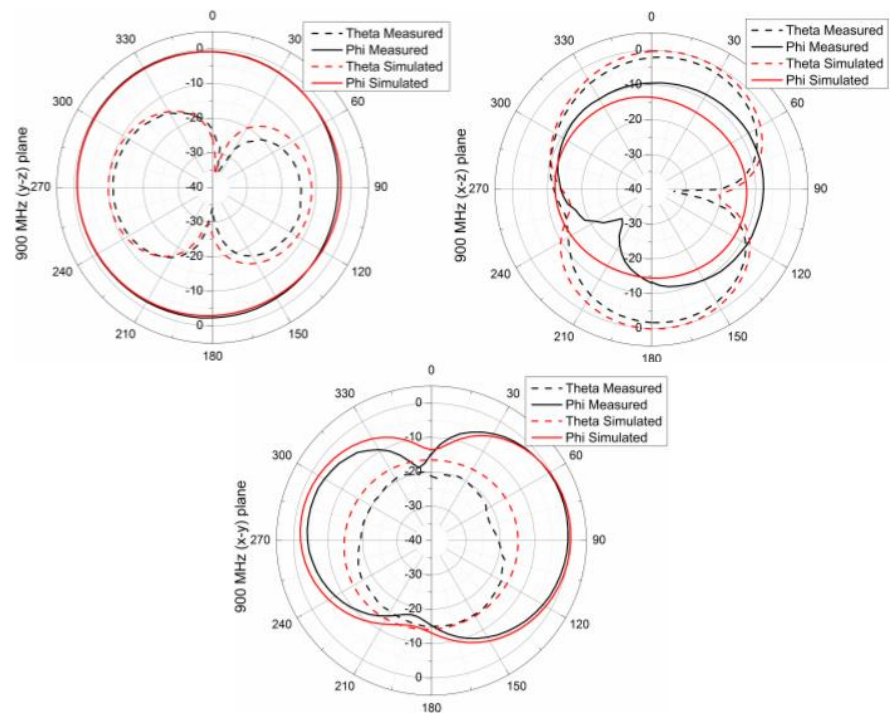

Fig. 10. Measured and simulated radiation patterns at $900 \mathrm{MHz}$.

\section{CONCLUSION}

In this paper, a dual band planar inverted-F-antenna for portable devices at 450LTE and GSM900 was presented. The low-cost antenna is easily fabricated covering the uplink band of 450LTE $(452-457 \mathrm{MHz})$ and GSM900 $(880-915 \mathrm{MHz})$ respectively. The proposed compact antenna offers good omnidirectional radiation characteristics, high measured total efficiency and realized gain at both bands. The antenna is low profile suitable to integrate into small envelopes with additional benefit of a large frequency-ratio range which is easy to control.

\section{REFERENCES}

[1] A. Frederich - Chairman WRC - 07 CPG presentation-page 9, http://rspg.ec.europa.eu/_documents/documents/meeting/rspg14/rspg14_ result_wrc.pdf.

[2] 3GPP TR 36.840 V12.1.0, Sep. 2013; 3rd Generation Partnership Project; Technical Specification Group Radio Access Network; LTE 450 $\mathrm{MHz}$ in Brazil Work Item Technical Report (Release 12)

[3] Anatel resolution $n^{\circ} 558 / 2010$, "Canalization rules and radio frequency usage conditions for the $450 \mathrm{MHz}$ to $470 \mathrm{MHz}$ band", December 2010.

[4] 3GPP TSG-RAN WG4, R4-130502, April 2013; "LTE $450 \mathrm{MHz}$ coexistence with Digital TV broadcast system," CPqD

[5] 3GPP TSG-RAN WG4, R4-131157, Feb. 2013; "Further consideration on frequency band arrangement", Huawei, HiSilicon

[6] 3GPP TSG-RAN4, R4-131660, April 2013; "LTE450 UE Self Desense", Motorola Solutions

[7] Sooliarn Ooi, Boon Ping Koh, Grosman, O. "Dual Band UHF-GPS Folded Monopole Antenna," in IEEE Antennas and Propagation Society International Symposium, 2007, pp. 1237-1240.

[8] Sooliam Ooi, Boon Ping Koh, "Single-fed Dual Band UHF-GPS Helical Antenna," in IEEE International Workshop on Antenna Technology (IWAT) 2006, March 2006, pp 184-187.

[9] W. Chen, Y. Yao, J. Yu, X. Liu, "Design of a novel multiband antenna for mobile terminals," in IEEE International Wireless Symposium (IWS), 2015.

[10] Z.D. Milosavljevic, “A Varactor-Tuned DVB-H Antenna," in Proc. iWAT Conf., 2007, pp. 124-127.

[11] L. Liu, J. Rigelsford, R. Langley, "Tunable Multiband Handset Antenna Operating at VHF and UHF Bands," IEEE Transactions on Antennas and Propagation, vol. 61, (7), pp. 3790-3796, March 2013.

[12] C. Niamien, S. Collardey, A. Sharaiha and K. Mahdjoubi, "Ultraminiature UHF antenna using magneto-dielectric material," IET Electronics Letters, vol. 47, (5), pp. 300-301, March 2011.

[13] P. Queffelec, J. F. Pintos, A. Louzir, P. Minard, J. Perraudeau, J. L. Mattei, and D. Souriou, 'Ultra-miniature UHF antenna using magneto dielectric material', ANTEM-AMEREM, 2010, pp. 1-4.

[14] M. Kyro, M. Mustonen, C. Icheln, C. Vainikainen, "Dual-element antenna for DVB-H terminal," in Loughborough Antenna and Propagation Conference (LAPC), March 2008, pp. 265-268.

[15] H. Wheeler, "The Radiansphere Around a Small Antenna," IEEE Proceedings of The I.R.E., vol. 47, no. 8, pp. 1325-1331, August 1959. 